\title{
Correction to: Enhanced Oral Absorption of Amisulpride Via a Nanostructured Lipid Carrier-Based Capsules: Development, Optimization Applying the Desirability Function Approach and In Vivo Pharmacokinetic Study
}

\author{
Abd El-Halim I. El Assasy, ${ }^{1}$ Nihal Farid Younes, ${ }^{1}$ and Amal I. A. Makhlouf ${ }^{1,2}$
}

Published online 25 February 2019

Correction to: AAPS PharmSciTech https://doi.org/10.1208/s12249-018-1283-x

The second author's name was incorrectly published as "Niha F. Younes". The correct name is "Nihal Farid Younes" as shown above in the list of authors.

Publisher's Note Springer Nature remains neutral with regard to jurisdictional claims in published maps and institutional affiliations.

The online version of the original article can be found at https:// doi.org/10.1208/s12249-018-1283-x

${ }^{1}$ Department of Pharmaceutics and Industrial Pharmacy, Faculty of Pharmacy, Cairo University, Kasr El Aini, Cairo, 12411, Egypt.

${ }^{2}$ To whom correspondence should be addressed. (e-mail: Amal.makhlouf@pharma.cu.edu.eg; amalibrahimmakhlouf@gmail.com) 